\title{
Natural infrastructure in urban and planning strategies in arid zones: case studies from Egypt
}

\author{
N. Mahmoud ${ }^{1,2} \&$ P. Selman ${ }^{2}$ \\ ${ }^{1}$ Cairo University, Egypt \\ ${ }^{2}$ Department of Landscape, University of Sheffield, UK
}

\begin{abstract}
Spatial planning strategies integrate multiple environmental, social and economic functions, and draw together the phases of physical planning, management, implementation and maintenance. Natural Infrastructure (NI) - a term that is used in preference to 'green infrastructure' to reflect the complementary importance of water systems and airsheds - is of growing importance to spatial planning. However, many planners fail adequately to address the multifunctional potential of NI and often equate it simply with the design of parks or open spaces. This paper considers NI as a system within an integrated planning process. The nature of NI differs significantly according to climatic zone, for example, whether the area is moist or arid. This paper will focus on arid environments in Egypt, and considers two NI projects that differ in terms of their core structure, ecological resources, cultural assets, multi-functional properties and scale. The first project is a corridor connecting urban areas along the Nile River and the second is a green network connecting different urban and natural areas within older districts. The paper concludes with an exploration of a theoretical model of NI adapted to the Egyptian context using IKONOS GIS maps of greater Cairo.

Keywords: planning strategy, Natural Infrastructure (NI), green infrastructure (GI), multi-functionality $(M F)$, cultural corridors, ecological corridors, green corridors.
\end{abstract}




\section{Introduction}

The term "Natural Infrastructure" (NI) is generally accepted as referring to 'green infrastructure' but also including non-green natural elements such as water systems and airsheds. Additionally, the term 'green infrastructure' implies that areas should be green: however, this is not always appropriate to arid countries, where maintaining 'green' habitats may require unsustainable types of irrigation. This paper will focus on Egyptian practices, in the light of current social and cultural perceptions which are often negative and uncaring towards green spaces, a tendency which Abdelhalim [1] suggests can partly be overcome by re-establishing cultural and community links with local spaces during planning and design processes.

Promoting natural infrastructure in Egypt needs to address two equally important issues: (1) an environmental problem, i.e. a lack of research and practical experience regarding the connections between parks and open spaces, coupled with an expectation for such spaces to be 'green', and (2) a governance problem, i.e. no tradition to prioritise and integrate greenspace systems during the strategic stages of planning.

\section{Green infrastructure in arid countries}

The term 'green infrastructure' is more popular in Europe and America than in Middle Eastern countries, possibly because in arid areas there is relatively little landscape that is naturally green. Furthermore, the cultural and historic aspects affect the understanding and experience of NI. Wescoat [8] reported that "the term "arid" has a range of connotations that vary by culture and historical period" (Wescoat [8] p. 11). Bashandy [5] drew attention to the establishment of greenways and green networks from the beginning of 20th century in Cairo, which has helped Cairo to become a liveable and more sustainable city.

\section{The irrigation system in arid areas}

Irrigation systems in arid areas should consume a minimum of water; Lyle [9] described a suitable irrigation system used in arid areas in America as comprising treated wastewater from a nearby Sewage Treatment Plant. Another point of view is that the irrigation system should reflect local cultural technologies: for example, the irrigation methods in Al-Azhar Park in Cairo are based on the pump and filtration station at the desert plant nursery from fresh water and others are based on watering by hand from rope-and-bucket wells. Gravity water is a main source of irrigation, particularly in areas far away from the Nile. Laird noted that most farming relies on water pumped directly from the Nile. However, further from the river, such as the shelterbelt or dune sites, pumps in matara wells can supply a simple canal and furrow system for shelterbelt irrigation on fairly level ground. 


\section{Natural infrastructure planning process}

Natural infrastructure is now considered as a fundamental design concept in different environmental projects. Ahern [3] suggested a spatial strategy for sustainable green infrastructure planning. It is conceptually aligned with the concept of GI by seeking new or innovative opportunities to provide functions in association with urban infrastructure. Also, RNRP [14] advocated that local authorities, environmental agencies, developers and stakeholders should work together to create new areas and to protect the natural and cultural environment. Therefore, this paper suggests a theoretical model that includes three elements, namely 1) policy framework, 2) governance framework; and 3) current experiences of spatial planning. Mahmoud and Selman [11] suggested model of six stages in Figure 1.

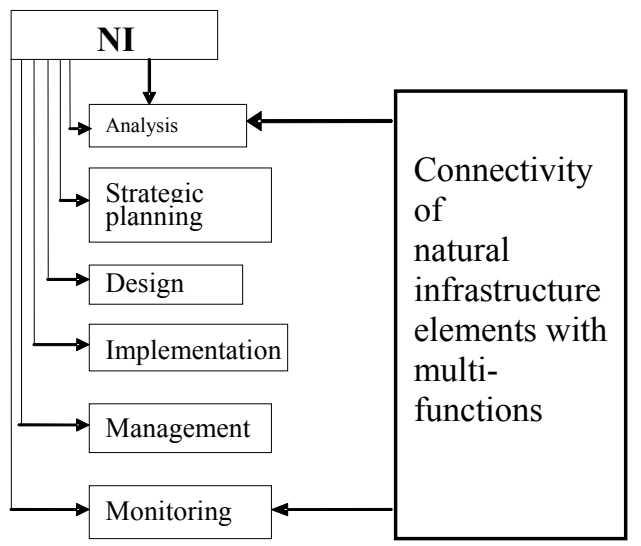

Figure 1: The steps of natural infrastructure planning connecting natural infrastructure in spatial planning in arid zones, Mahmoud and Selman [11].

\section{General overview of Egyptian planning strategy}

Cairo has a long history of green infrastructure as an agricultural resource and as heritage ecological corridors. All agricultural lands are based on the core natural corridors of the irrigation system which comprises the Nile and its tributaries. "No large open green space existed in the urban core of medieval Cairo, and to some extent this was true of most cities of the central Islamic land between the eighth and nineteenth centuries. This is due in part to the arid climate prevalent in most Middle Eastern regions which made the maintenance and irrigation of green space a very difficult and costly procedure." Rabbat [13]. Historically, therefore, green spaces were only provided in palace precincts, for which government dispensation was given to abstract irrigation water from the Nile. Here, the Egyptian Government adopted a program of reviving green spaces and networks in Cairo to meet the needs of communities from open green areas 


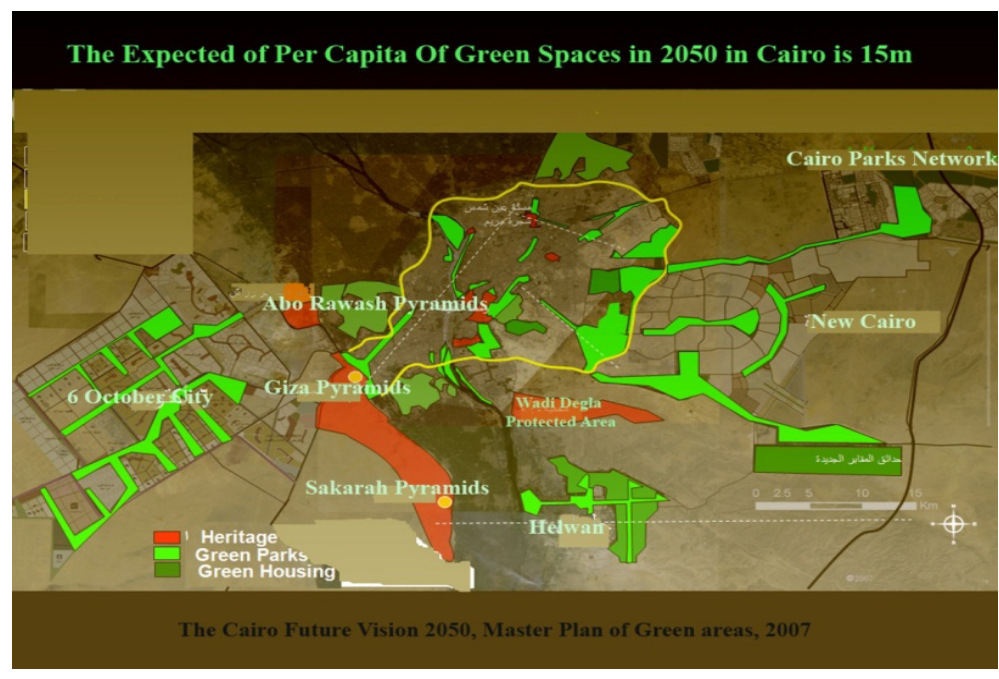

Figure 2: $\quad$ Master plan of expected green areas in Cairo in 2050. The Cairo Future Vision 2050, GOPP [7].

within a good transportation network. GOPP [7] reported in the Master Plan of Green Spaces in Cairo Future Vision 2050 that the expected per capita greenspace provision will be increased to $15 \mathrm{~m}^{2}$ by developing open spaces within Cairo. Total green spaces will then amount to 20.000 ha, Figure 2.

\section{Case studies in Egypt}

Choice and analysis of case studies was based on location, climate, scale, current state of progress, connectedness of the existing network, multi-functionality, density of vegetation, and public involvement. The cases are located in Cairo, Egypt which has an annual rainfall of about $165 \mathrm{~mm}$ (no rainfall June-August) and temperatures of $19-34^{\circ} \mathrm{C}$ in summer and $9-14^{\circ} \mathrm{C}$ in winter. The first case study is located around the River Nile and includes three islands which are connected by linear natural (green and blue) corridors. The second case comprises a green network of connected open spaces, residential areas, ecological areas, and a new urban development.

\subsection{The methods used for analysis case studies}

Case study investigation has been based on three methods, all of which are under further development at the time of writing. First, a rapid field appraisal and visual survey has been undertaken. Second, interviews have been conducted with academics, professionals and government officials. These covered: current and proposed approaches and polices of NI in Egypt; multi-functionality; principles and guidelines for design, planning and management; and maintenance, 
implementation and funding. The third and current phase of the research involves examination of the natural infrastructure in Cairo through GIS mapping (ArcView 9.3) of current structure, multiple-use and connectivity, and the potential for its reinforcement. GIS mapping comprises analysis of (1) environmental features, and (2) governance/ cultural issues such as, typology, land use, open green areas, roads, trails, water resources and ecological areas. Careful processing of data can result in acceptably low error rates. Moreover, GIS is a good technique for connecting environmental and governance issues through overlapping its data on different layers. To date, this has entailed updating the IKNOS $^{\odot}$ GIS base map of Cairo with 2007 satellite imagery and information, based on planning reports and site visits, in order to gather information about geographical and geological features, landmarks, heritage assets, green spaces, protected areas and proposed future projects. Salama et al [15] proposed a similar methodology for protected areas and natural networks.

\subsection{The first case: green corridor along the River Nile}

\subsubsection{Background}

The River Nile in Egypt is regarded as an important natural corridor linking Upper and Lower Egypt. In Cairo it connects different urban districts of different characters and it plays a key functional role in the city. The Nile corridor has different route connectors including the Historic route that links historic Cairo with main road (Salah Salem) and the Recreation route connecting the network of open spaces.

\subsubsection{The aim of this case study}

The major aim is to study the ability of River Nile as a natural blue way to connect cultural, historical, touristic and recreational features. Connection will involve developing visual and movement corridors along River banks, and improving access to the River through the city as well as the ease of movement along the river.

\subsubsection{Planning strategy}

Barada et al [4] have developed a 'strategic vision' for a River Nile masterplan which includes policy proposals that provide a framework for natural infrastructure, namely: preserve agricultural lands on the north and south banks of the urban area and the Nile islands; control the growth of urban communities through the protection of rural space; and solve the problems of urban sewage and agricultural drainage. In this vision, Barada et al [4] recommended designating all the Nile islands as protected areas. Currently, these are used for residence and agriculture and some have only water-borne access. In addition, the river banks are, or have potential to be, recreational riverside greenways that include cycleways along the river, pedestrian paths, open green spaces, parks and green space parallel to the Nile especially in urban and recreational sectors, Figure 3. 


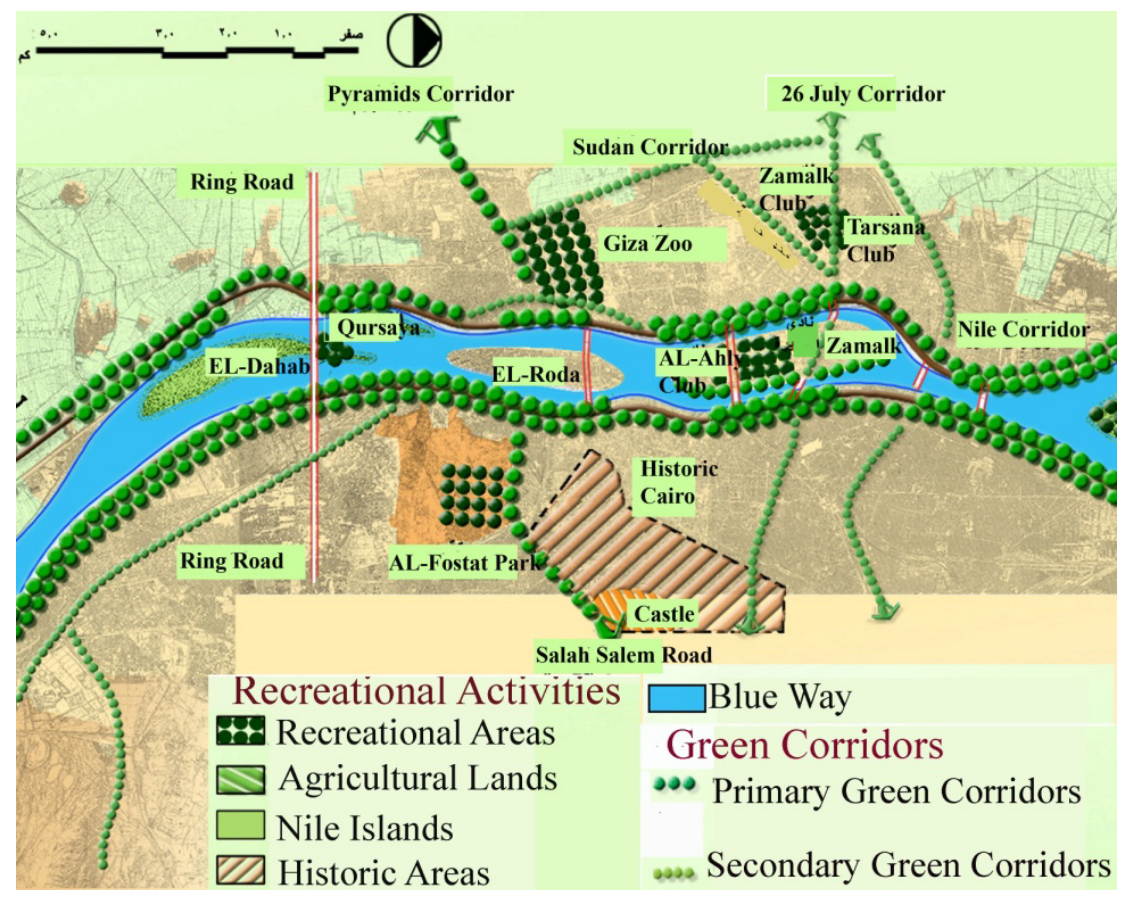

Figure 3: Master plan of green corridors in Greater Cairo (Barada et al [4], master plan of Nile River Banks in Greater Cairo).

\subsubsection{The status of this case}

The masterplan project began in 2001 as a condition survey of the Nile Banks and was further developed in 2005 to promote a new planning strategy vision for the Nile within Cairo, as a basic core for functional and recreational features.

\subsubsection{Multiple functions}

The river is seen as the backbone of a major recreational network linking the tourism and entertainment hub of the River Nile (banks and islands) with green / open spaces, and archaeological / cultural areas within Greater Cairo. It takes into account the needs of economic activities associated with the River Nile (e.g. tourism, marinas, river transport and industry) and entails extensive landscaping of the communication network (greyways) and central and commercial areas Barada et al [4].

\subsubsection{River Nile projects}

There are three main projects in the study area, all of them aiming to develop the River Nile corridor and connect it with other surrounding areas and functions, namely:

1. Re-organisation of the Nile Marinas (top priority project).

2. The development of the Nile Port (Ather Elnaby Port) in an area fronting onto Abu Eldahb Island (with agricultural and recreational 
areas and accessible by road and underground rail).The rationale is based on relocating industrial activities to reduce pollution and creating a recreational greenway of parks, open spaces.

3. The development of Syalt El-Roda Banks. The Island of Syalt ELRoda is considered a visual-historic area possessing many landmarks and the narrows surrounding this island create potential for riparian links.

\subsubsection{Management and implementation}

Phased implementation began in 2007, with the Touristic Ministry having lead responsibility and co-ordinating other organisations, such as the General Organisation of Touristic Development and the Centre of Research and Urban Studies at Cairo University. The key local authorities have also been involved in funding and implementation. However, there is no official entity that serves as a connection between these organizations. Accordingly, Barada et al [4] suggested the Egyptian Environmental Affairs Agency of the Council of Ministers itself or other administrative authority, could achieve a kind of integration and coordination and have ultimate responsibility. It should be borne in mind that creating a new administrative entity can increase overlap and conflict, if its tasks are not tightly and accurately formulated.

\subsection{Case study 2: green network in Maadi}

\subsubsection{The historical development of Maadi}

The land of Maadi district was agricultural when the first railway for mines was established in 1873 . The design of the town was based on nodes and a radial

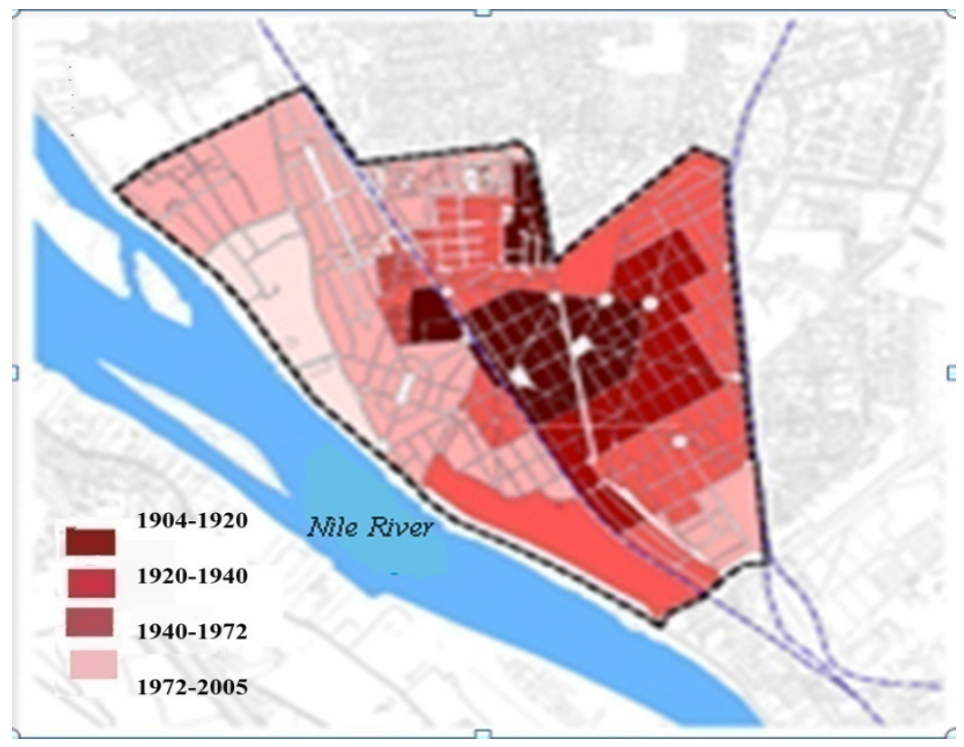

Figure 4: The historical development of Maadi district, Raafat et al [12]. 
transport axis, with parks and public lands. During the early $20^{\text {th }}$ century it was mainly residential but there has been subsequent development of commercial units, small factories, and military training areas. In 1952, some villas were converted to public schools and there was growth of administrative and political services, Figure 4.

\subsubsection{The status of this case}

This case is a project that aims to restore the ecological, historical and environmental balance such as, the blue way of AL-Khashab tributary and to maintain and preserve the native plants and improvement of natural soil. Additionally, it aims to link the protected area (Wadi Degla) and Maadi district by ecological corridor though investment the natural and ecological features.

\subsubsection{The potential of the study area}

There are four specific potentials of Maadi district that make this district visually distinct, and environmentally and historically valuable. First, the western frontage of Maadi district is exposed to the Nile, which gives the location its unique urban character and recreational value. Second, the preservation of valuable and historic buildings gives this district special visual character such as classic, new classic and Victorian houses. Third, the recreational and environmental places are spread as a green network and the historic blue way (AL-Khashab tributary) is considered to be a natural recreational way crossing

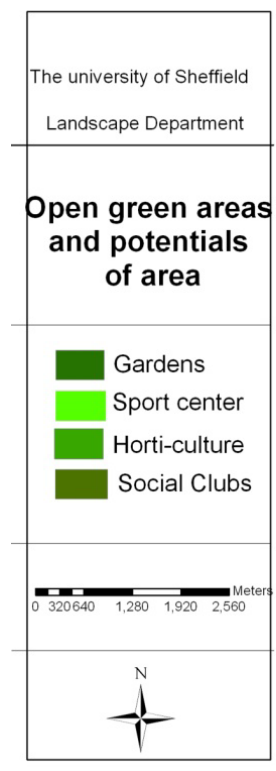

Figure 5: The potential of Maadi study area, GIS map by author.

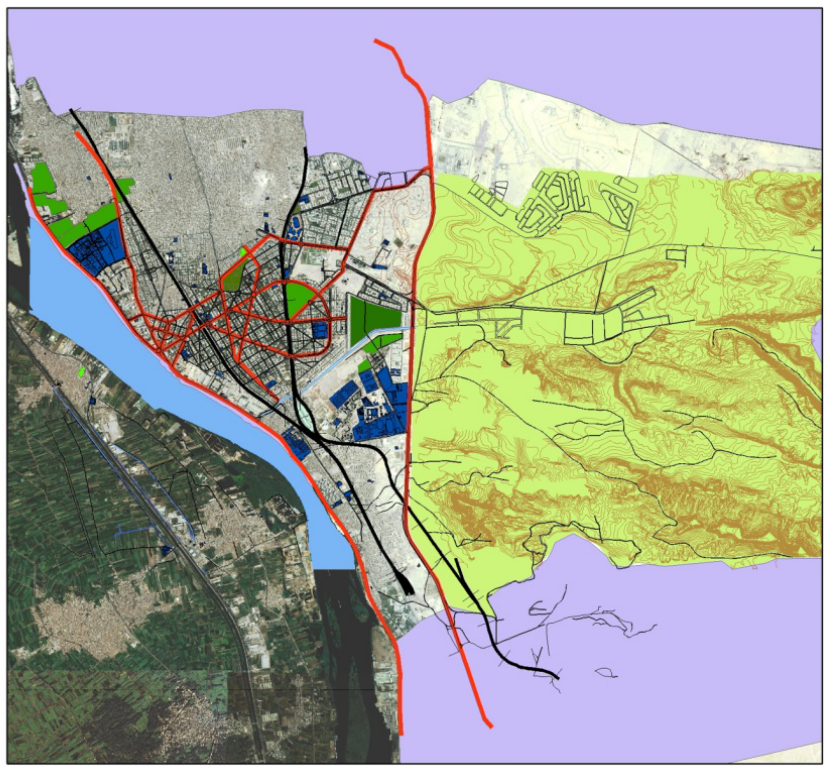


this district. Third, the location of Maadi district near the Wadi Degla Protected gave this district special individual character. Fourth, the planning concept of this district makes the creation of green network easier, because the simplicity of road design produces a more harmonious urban spatial form, in contrast to the morphology of Cairo, Figure 5.

\subsubsection{Surrounding land use}

Four main types of land use surround the Maadi district: the River Nile; the railway; a natural protected area; and old and new residential areas. These have positive and negative effects on the uses of the study area. For instance, the Maadi district's entrances from the edge of the River Nile provide major opportunities for recreation and tourism; and the Wadi Degla gives this district special natural character, notably for biodiversity. By contrast, to the north is a slum district, with associated social issues.

\subsubsection{Green network}

The green network concept is based on the city's radial grid, whose nodes have a historic value as well as rare plants with a higher density of trees. Road verges and green pedestrian paths connect the nodes and green open spaces. Maadi district is also a key water catchment and includes canals and conduits along drainage buffers.

\subsubsection{The vegetation, water system and maintenance}

Many important plants have colonised Maadi district since its establishment in 1873, broadly comprising grasses, shrubs, and palm trees. Raafat et al [12] proposed a natural infrastructure based on grassy areas comprising species requiring little water and tolerating intensive use, a colourful choice of flowering shrubs with low water and maintenance demands, and palm trees emphasising the shape of nodes and the urban entrance. The main blue corridor, the River Nile, skirts Maadi district from the west. The Al-Khashab tributary had been converted to a pedestrian path but Raafat et al [12] preferred its restoration as a scenic blueway. Its edges are now used as pedestrian paths and it will be supplied with water from the River Nile and furnished with native stones and rocks.

\subsubsection{Management and implementation}

The development of green network of Maadi as a multicultural distinctive network will be in two levels - an urban management phase, and an implementation phase. The Urban Management phase will comprise three tiers of organisation, namely, local government (council), a nongovernmental organization (NGO), and private sector (stakeholders - Maadi Company). The NGO has a particular role to manage urban projects and urban decisions, and there is a sharing of responsibility between the council and the Maadi Company for building process and guidelines. The Implementation Phase entails cooperation between government and private sectors in order to sustain momentum. Raafat et al [12] reported that there are three levels of implementation - long-term, medium-term and short-term projects. 


\section{Conclusion}

From the interviews, it is evident that the vast majority of Egyptian planners such as Steno [16] argues that there are specific three points to be taken into account when creating or developing natural infrastructure projects. First, natural infrastructure requires a lead organization with a specific brief to integrate terms of reference and the actions of partner organisations. Second, NI should be recognised in the basic and connecting layers of a spatial planning strategy that involves a wide spectrum of participants and ensures timely implementation. Third, Abo EL-Soud [2] emphasises that natural infrastructure data should be covered via a GIS system that helps the implementation and maintenance of a project, and successful co-operation during the planning process.

From this initial analysis of case studies, the paper identified the complementarily of blue and green infrastructure within an overall planning approach based on irrigation systems, planning sectors (cultural, social, economic, urban) and historic urban development patterns. Additionally, various lessons can be drawn from these case studies in relation to the planning strategy and its implementation, and in relation to the irrigation system.

\subsection{In relation to the planning strategy and its implementation}

- Developing the multiple functions of greenways and green corridors, e.g. recreation, social interactions, preservation of cultural and historical features, and climate regulation.

- During the planning process, it is important to involve and educate all stakeholders in design and implementation, so that NI is incorporated as a basic layer at every stage.

- There is a need for a flexible approach to the incorporation of NI relating to project-specific requirements, such as long-term management, networking of community leaders in management and increasing the role of key government agencies.

\subsection{In relation to irrigation systems}

- The irrigation system in arid areas depends on re-cycling waste-water (grey water) and using special native plants.

- $\quad$ NI comprises both a green and blue infrastructure that makes the most of natural resources and environmental sites, associated with water systems and natural corridors.

Finally, natural infrastructure should be clearly defined, not only focusing on and limited to green spaces, but broadened to include natural and environmental resources.

\section{References}

[1] Abdelhalim, A.I. (1996) Culture, environment, and sustainability: theoretical notes and reflections on a community park project in Cairo. 
Sustainable Landscape Design in Arid Climates. Aga Khan Trust for Culture, Geneva.

[2] Abo EL-Soud, T. Interview, 10 March 2009, Expert in Geo-informatics system \& mathematical, spatial modelling econometrics, School of Urban Planning, Faculty of Urban \& Regional Planning, Cairo University, Cairo.

[3] Ahern, J. Greenways as a planning strategy. Landscape and Urban Planning, 33, pp. 131-155, 1995.

[4] Barada, A., Steno, M., Tulan, N. \& Yousry, M., Master plan of River Nile banks of greater Cairo. Faculty of Regional and Urban Planning, Cairo University, Cairo, 2005.

[5] Bashandy, S., The watercourses within the framework of system ideology themes for environmental and green corridors. Al-Azhar Engineering International Conference (AEIC), Al-Azhar University, 2003.

[6] Benedict, M.A., A strategic approach for land conservation: Green infrastructure. The Conservation Fund, Arlington, VA, 2000.

[7] General Organization of Physical Planning (GOPP), Cairo future vision 2050. Ministry of Housing, General Organization of Physical Planning, Cairo. 2007.

[8] James L. Wescoat. J., A Geographical Perspective on Landscape Design in Arid Environments. Sustainable Landscape Design in Arid Climates, Aga Khan Trust for Culture, Geneva, 1996.

[9] Lyle, J. T., Archetypes in arid landscapes. Sustainable landscape design in arid climates. Aga Khan Trust for Culture, Geneva, 1996.

[10] Laird, P., People, trees, and desert: village protection in Northern Sudan. Sustainable landscape design in arid climates. Aga Khan Trust for Culture, Geneva, 1996.

[11] Mahmoud, N. \& Selman, P., Connecting natural infrastructure in spatial planning in arid zones. Ecological networks: Science and practice, $16^{\text {th }}$ Annual Iale UK Conference, Edinburgh University, UK, 2009.

[12] Raafat, A., EL-Sawy, A., Abdallah, A., \& Wageh, A., The upgrading of urban environment and preservation of urban character of greater Cairo. Maadi area. Cairo. The General Organization of Physical Planning, Cairo, 2005.

[13] Rabbat, N., A Brief History of Green Spaces in Cairo. S. Bianca \& P. Jodidio (Eds). Cairo: Revitalising a Historic Metropolis. Turin: Umberto Allemandi \& Co. for Aga Khan Trust for Culture, Turin, pp. 43-53, 2004.

[14] River Nene Regional Park (RNRP) Green Infrastructure: Making the Connection, RNRP, Northampton, 2006.

[15] Salama, A., Shaker, M., \& Abdalla, A., Management Plan for Wadi Degla Protected Area, Cairo. Egyptian Environmental Affairs Agency, Cairo, 2005.

[16] Steno, M. Interview, 15 March 2009, Ex-Dean of Faculty of Urban \& Regional Planning, Cairo University, Cairo. 